\title{
Relationship between pregnancy rate and number of intrauterine insemination cycles during the study of comparative efficacy of letrozole and clomiphene citrate adjuvants to gonadotropin stimulation in controlled ovarian stimulation cycles combined with intrauterine insemination therapy
}

\author{
Pankaj Sharma $^{1 *}$, Ashok Verma1, Kritika Katoch ${ }^{2}$
}

${ }^{1}$ Department of Obstetrics and Gyanecology, DRRPG Medical College, Tanda, Kangra, Himachal Pradesh, India

${ }^{2}$ Zonal Hospital, Dharamshala, Kangra, Himachal Pradesh, India

Received: 10 November 2021

Revised: 01 December 2021

Accepted: 02 December 2021

\author{
*Correspondence: \\ Dr. Pankaj Sharma, \\ E-mail: docpank9090@gmail.com
}

Copyright: () the author(s), publisher and licensee Medip Academy. This is an open-access article distributed under the terms of the Creative Commons Attribution Non-Commercial License, which permits unrestricted non-commercial use, distribution, and reproduction in any medium, provided the original work is properly cited.

\begin{abstract}
Background: Infertility is commonly defined as the failure of conception after at least twelve months of unprotected intercourse. Factors contributing are both male and female in which unexplained etiology accounts for 51\%, male factor $28 \%$, endometriosis $17 \%$ and ovulatory disorders $4 \%$.

Methods: Prospective, randomized study was conducted at DRRPG medical college, Tanda, Kangra, Himachal Pradesh. In our study, patients were randomized into two groups of 30 each. Women in group A received clomiphene citrate $100 \mathrm{mg}$ /day and group B received letrozole $2.5 \mathrm{mg}$ /day from day 3-7 of menstrual cycle. All the patients received human menopausal gonadotropin $75 \mathrm{U}$ given every alternate day from day 5 until HCG administration. Ovulation was triggered with recombinant HCG (5000 IUIM) when the dominant follicles reached $18 \mathrm{~mm}$ in diameter. A single IUI was performed 36 hours later. A maximum of four cycles were given.

Results: In our study, total number of induction cycles given in group A and B were 120 and 114 respectively. Out of these, 112 and 111 IUI cycles were done in group A and B respectively. A pregnancy rate of $1.66 \%$ and $7.87 \%$ per IUI cycle was observed in group A and B respectively. Thus it is concluded that the pregnancy rates were significantly higher in letrozole group (30\%) in comparison to clomiphene citrate group $(6.66 \%)$.

Conclusions: Aromatase inhibitor letrozole appears to constitute a good alternative to clomiphene citrate in patients with unexplained infertility undergoing gonadotropin-stimulated COS cycles combined with IUI therapy.
\end{abstract}

Keywords: Letrozole, Clomiphene citrate, FSH, Intrauterine insemination

\section{INTRODUCTION}

It is very difficult to come to this final conclusion which is the best drug used for ovarian stimulation. For more than four decades, clomiphene citrate is used as the first line of treatment for ovulation disorders. ${ }^{1,2}$ Disappointing results are seen due to its peripheral antiestrogenic effects. $^{3,4}$ Nowadays the most commonly drugs used for ovulation induction is clomiphene citrate and letrozole. Clomiphene citrate being an agonist and antagonist of estrogen acts as a competitive estrogen antagonist at physiological female estrogen levels where as letrozole being a third-generation aromatase inhibitor inhibits estrogen production and increases the formation of GnRHa and follicle stimulating hormone. Letrozole is reported with an acceptable pregnancy outcomes and 
lower rate of multiple gestation. These ovulation inductions drugs are nowadays used in combination with intrauterine insemination in treatment of infertility cases.

Among many methods, superovulation and intrauterine insemination (IUI) is an effective treatment in patients with unexplained infertility. ${ }^{5}$ Superovulation acts by increasing the recruitment of number of oocytes suitable for fertilization or by correcting any subtle defect in ovulation which leads to increase in conception rates. It also responsible for increasing the quantity of motile sperms reaching the fallopian tubes and it is also useful in cases of infertility due to cervical factors. ${ }^{6}$

\section{METHODS}

The prospective randomized controlled study was based on couples attending the infertility clinic in the department of obstetrics and gynaecology at DRRPGMC, Tanda, Kangra, Himachal Pradesh suffering either from primary or secondary infertility lasting from February 2019 to January 2020.

\section{Inclusion criteria}

All couples with unexplained infertility and women between 18 to 37 years of age with patent tubes, normospermic male partner as per WHO guidelines liquefaction complete in $30 \mathrm{mins}$, volume $1.5 \mathrm{ml}$, color opalescent white, concentration (ml) 15 million, progressive motility $32 \%$, vitality $58 \%$, morphology $4 \%$.

\section{Exclusion criteria}

All the following couples are excluded with females $>37$ years, female with severe endometriosis (stage 4), basal serum $\mathrm{FSH}>15 \mathrm{MIU} / \mathrm{ml}$, couples with IUI $>5$ cycles, Women with endocrinological disorders in the form of thyroid dysfunction, hyperprolactinemia and cushing syndrome and patient not willing to participate in the study. The detailed demographic and infertility characteristics of sampled women were recorded that included clinical details regarding the age, chief complaints with duration, obstetrical history, Socioeconomic status and personal history. Examination included general physical examination, systemic examination, per abdominal, per speculum and vaginal examination. Patients were divided into two groups. Group A: women in this group received clomiphene citrate $100 \mathrm{mg} /$ day from day 3-7 of menstrual cycle and human menopausal gonadotropin $75 \mathrm{U}$ given every alternate day from day 5 till HCG administration._Group B: Women in this group received letrozole from day 3-7 of menstrual cycle and human menopausal gonadotropin $75 \mathrm{U}$ given every alternate day from day 5 till HCG administration. Patients will be monitored by transvaginal ultrasound folliculometry from day 11 on every alternate day until HCG administration. The patient was then evaluated regarding the number and size of the follicles and endometrial thickness. Endometrial thickness was measured on TVS at the great diameter perpendicular to the mid sagittal plane in the fundal region including both layers of endometrial cavity

Once a dominant follicle size of $\geq 18 \mathrm{~mm}$ was visualized in ultrasound, a HCG trigger was given intramuscularly with a dose of 5000 IU. Following which IUI was done after 36-48 hrs. Density gradient method was used as method of sperm preparation. Patients were sent home with progesterone support of $300 \mu \mathrm{g}$ of micronized progesterone for 14 days. A maximum of four cycles were given.

\section{Statistical analysis}

Sample size was studied before the start of the study. Means, standard deviations, medians and ranges were calculated for descriptive purposes. Comparisons of patient characteristics, response to stimulation regimes, pregnancy rates per cycle, average number of follicles per cycle and average follicle size per cycle were done using chi-square test and student $\mathrm{t}$ test, $\mathrm{p}<0.05$ was considered statistically significant.

\section{RESULTS}

The basic characteristic of both the population are depicted in Table (1-4). Parameters such as age, obstetrics index, BMI, family and past history of blood sugar abnormality, history of abortion, mode of conception was compared and found to be significantly different in both the groups.

Table 1: Distribution of patients according to age.

\begin{tabular}{|llllll|}
\hline $\begin{array}{l}\text { Age of the patient } \\
\text { (years) }\end{array}$ & \multicolumn{2}{l}{ Group A } & \multicolumn{2}{l|}{ Group B } & P \\
& $\mathbf{N}$ & \% & N & \% & value \\
\hline $\mathbf{2 5}$ & 6 & 20 & 7 & 23.33 & 0.75 \\
\hline $\mathbf{2 6 - 3 0}$ & 14 & 46.66 & 13 & 43.33 & 0.79 \\
\hline $\mathbf{3 1 - 3 5}$ & 8 & 26.66 & 7 & 23.33 & 0.76 \\
\hline $\mathbf{> 3 5}$ & 2 & 6.66 & 3 & 10 & 0.64 \\
\hline Mean age & 29.133 & 29.066 & \\
\hline
\end{tabular}

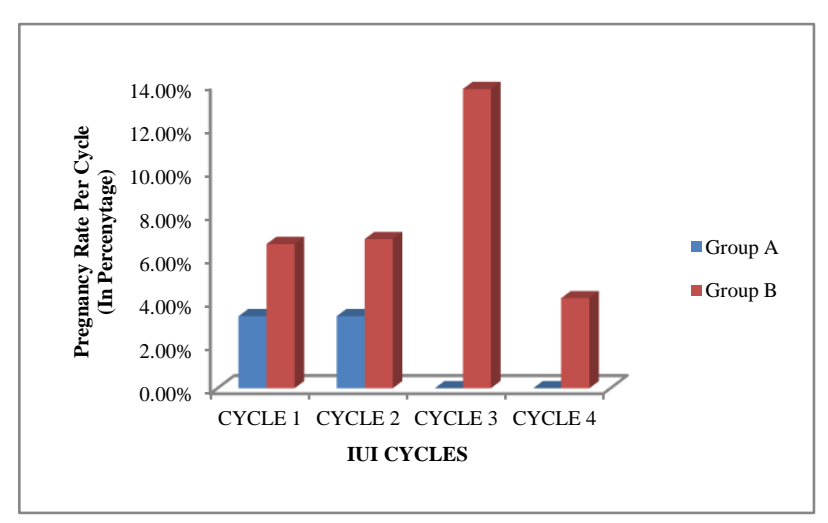

Figure 1: The comparison of pregnancy rate for IUI cycle in both the groups where group $A$ is clomiphene citrate group and group B is letrozole group. 
Table 2: Ddistribution of patients according to socioeconomic status.

\begin{tabular}{|llllllll|}
\hline \multirow{2}{*}{ Socioeconomic status } & \multicolumn{2}{c}{ Group A } & \multicolumn{2}{c}{ Group B } & \multicolumn{2}{c|}{ P value } \\
\hline Lower & N & \% & PREG & N & \% & PREG & 0.02 \\
\hline Middle & 20 & 66.66 & 01 & 10 & 33.33 & 02 & 0.02 \\
\hline Total & 10 & 33.33 & 01 & 20 & 66.66 & 07 & - \\
\hline
\end{tabular}

Table 3: Ddistribution of patients according to duration of marriage.

\begin{tabular}{|lllllll|}
\hline Duration of marriage & \multicolumn{2}{c}{ Group A } & Group B & P value & Significance \\
(years.) & N & $\mathbf{\%}$ & N & \% & & NS \\
\hline$<\mathbf{5}$ & 24 & 80 & 19 & 63.33 & 0.25 & S \\
\hline $\mathbf{5 - 1 0}$ & 02 & 6.66 & 10 & 33.33 & 0.02 & NS \\
\hline$>\mathbf{1 0}$ & 04 & 13.3 & 01 & 3.33 & 0.35 & - \\
\hline Total & 30 & 100 & 30 & 100 & - & \\
\hline
\end{tabular}

Table 4: Distribution of patients according to obstetric history.

\begin{tabular}{|llllll|l|}
\hline & \multicolumn{2}{l}{ Group A } & \multicolumn{2}{l}{ Group B } & P value & Significance \\
\hline Obstetric history & N & \% & N & \% & & NS \\
\hline Primary infertility & 23 & 76.66 & 22 & 73.33 & 0.76 & NS \\
\hline Secondary infertility & 07 & 23.33 & 08 & 26.67 & 0.76 & NS \\
\hline Previous abortion & 01 & 3.33 & 03 & 10 & 0.60 & NS \\
\hline Previous term pregnancy & 06 & 20 & 04 & 13.33 & 0.72 & NS \\
\hline $\begin{array}{l}\text { Previous ectopic } \\
\text { pregnancy }\end{array}$ & 00 & 00 & 01 & 3.33 & 0.31 & \\
\hline
\end{tabular}

Table 5: Number of couples undergoing IUI cycle and comparing their pregnancy rate.

\begin{tabular}{|lllllll|}
\hline IUI cycle & $\begin{array}{l}\text { No. of couples in different } \\
\text { cycles }\end{array}$ & Pregnancyduring cycles & \multicolumn{2}{l|}{$\begin{array}{l}\text { Pregnancy rate per cycle of } \\
\text { IUI (\%) }\end{array}$} \\
& Group A & Group B & Group A & Group B & Group A & Group B \\
\hline $\mathbf{1}$ & 30 & 30 & 01 & 02 & 3.33 & 6.66 \\
\hline $\mathbf{2}$ & 30 & 29 & 01 & 02 & 3.33 & 6.89 \\
\hline $\mathbf{3}$ & 30 & 29 & 00 & 04 & 00 & 13.79 \\
\hline $\mathbf{4}$ & 30 & 24 & 00 & 01 & 00 & 4.16 \\
\hline Total & 120 & 114 & 02 & 09 & 1.66 & 7.87 \\
\hline
\end{tabular}

An attempt was made to find the relationship between pregnancy rate and number of cycles. In our study, total numbers of induction cycles given in group A were 120 and in group B it was 114. Out of these, 112 IUI cycles were done in group A whereas 111 IUI cycles were done in group B. pregnancy rate of $1.66 \%$ per IUI cycle was observed in group A whereas a pregnancy rate of $7.87 \%$ per IUI cycle was observed in group B. The pregnancy rate per cycle in our study is mentioned as below: as per our observations, following inference can be given: letrozole group has a higher pregnancy rate per cycle in comparison to clomiphene citrate group. Pregnancy rates were higher in first 2 cycles in both the groups.

\section{DISCUSSION}

In our study, it was seen that pregnancy rates were $6.66 \%$ in group A and $30 \%$ in group B which is clinically and statistically significant. In a similar study conducted by Fozan et al it was observed that the pregnancy rate per cycle was $11.5 \%$ in the letrozole group and $8.9 \%$ in theclomiphene citrate group. ${ }^{8}$ Pourali et al also observed that clinical pregnancy rate was $16(18.4 \%)$ in clomiphene citrate+HMG group whereas in letrozole+HMG group, it was $26(31.3 \%)$ and Bayar et al in their study observed a pregnancy rate $(\%)$ of $5 / 52$ $(10 \%)$ in letrozole group and 8/67 (12\%) in clomiphene citrate group. ${ }^{7,9}$ Thus letrozole has a significantly higher pregnancy rate than clomiphene citrate group. In a similar study by Azantee et al they observed that most of the pregnancies were obtained within the first few IUI cycles. 
The clinical pregnancy rate increases until third cycle attempt but decreased after the fourth cycle..$^{10}$ Jellad et al, Allegra et al also confirmed these finding. ${ }^{12.13}$ Smith et al in their study also reported that pregnancy rates are significantly lower after the third IUI cycle, irrespective of the method. ${ }^{11}$ Above studies also concluded that after three IUIs without achieving a pregnancy we generally should move on to IVF treatment.

\section{CONCLUSION}

It is estimated that infertility affects $10-14 \%$ of the Indian population and continues to pose a great problem in the country including the state of Himachal Pradesh. Fortunately, however, the modern technology has offered solutions such as IUI and ART to solve this problemIn this paper, we represent a relationship between pregnancy rate and number of intrauterine insemination cycles during the study of comparative efficacy of letrozole and clomiphene citrate adjuvants to gonadotropin stimulation in controlled ovarian stimulation cycles combined with intrauterine insemination therapy. It is concluded that the pregnancy rates were significantly higher in Letrozole group $(30 \%)$ in comparison to clomiphene citrate group $(6.66 \%)$. This is important as IUI being a low cost procedure can be a very effective method for treatment of infertility in low socioeconomic countries like India where not every person can afford treatment options like In-Vitro Fertilization which being a costly procedure. Using ovulation induction drugs like letrozole with good efficacy along with IUI breaks this cost effective barrier making it an accessible tool for everyone.

Funding: No funding sources

Conflict of interest: None declared

Ethical approval: The study was approved by the Institutional Ethics Committee

\section{REFERENCES}

1. Kistner RW. Induction of ovulation with clomiphene citrate (clomid). Obster Gynecol Surv. 1965;20:873900.

2. Adashi EY. Clomiphene citrate mechanism and site of action. Fertil Steril. 1984;42:331-44.

3. Gonen Y, Casper RF. Sonographic determination of a possible adverse effect of clomiphene citrate on endometrial growth. Human Reprod. 1990;5:670-4.

4. Randall JM, Templeton. A cervical mucus score and in vitro sperm mucus interaction in spontaneous and clomiphene citrate cycles. Fertil Steril. 1991;56:4658 .
5. Costello MF. Systemic review of the treatment of ovulatory infertility with clomiphene citrate and intrauterine insemination. Aus J Obstet Gynaecol. 2004;44(2):93-102.

6. Tehrani NE, Abediasl Z, Rashidi BH. Comparison of the efficacy of the aromatase inhibitor Letrozole and Clomiphene citrate gonadotropins in controlled ovarian hyperstimulation: a prospective, simply randomized, clinical trial. J Assist Reprod Genet. 2008;25:187-90.

7. Pourali L, Ayati S, Tavakolizadeh S. Clomiphene citrate versus Letrozole with gonadotropins in intrauterine insemination cycles: A randomized trial. Int J Reprod Bio Med. 2010;5:49-54.

8. Fozan HA., Khadouri MH., Tan SL. Randomized trial of Letrozole versus clomiphene citrate in women undergoing superovulation. Fertil Steril. 2004;82: 1561-3.

9. Bayar U, Tanriverdi HA, Barut A. Letrozole vs. clomiphene citrate in patients with ovulatory infertility. Fertil Steril. 2005;85(4):1045-8.

10. Azantee YW, Murad ZA, Roszaman R. Associated factors affecting the successful pregnancy rate of intrauterine insemination at Internat ional Islamic University Malaysia Fertility Centre Med J. 2011;66(3):195-8.

11. Smith JF, Eisenberg ML, Millstein SG. Fertility treatments andoutcomes among couples seeking fertility care: data from prospective fertility cohort in the United States. Fertil Steril. 2011;95(1): 79-84.

12. Allegra A, Marino A, Coffaro F. GnRH antagonistinduced inhibition of the premature LH surge increase pregnancy rates in IUI stimulated cycles. A prospective randomized trial. Hum Reprod. 2007; 22(1):101-8.

13. Jellad S, Balsy M, Chibani M. Predictive factors for intrauterine insemination success: Analysis of semen parameters affecting outcome. Int J Uro. 2014;12(1): $1-7$.

Cite this article as: Sharma P, Verma A, Katoch K. Relationship between pregnancy rate and number of intrauterine insemination cycles during the study of comparative efficacy of letrozole and clomiphene citrate adjuvants to gonadotropin stimulation in controlled ovarian stimulation cycles combined with intrauterine insemination therapy. Int J Reprod Contracept Obstet Gynecol 2022;11:106-9. 